\title{
La competencia por el aplauso en las tablas del Siglo de Oro: de Lope de Vega a los pájaros nuevos ${ }^{\top}$ Competition for applause in the Golden Age theater
}

\section{Ignacio Arellano}

GRISO-Universidad de Navarra

ESPAÑA

iarellano@unav.es

[Hipogrifo, (issn: 2328-1308), 5.1, 2017, pp. 57-71]

Recibido: 13-12-2015/ Aceptado: 19-01-2016

DOI: http://dx.doi.org/10.13035/H.2017.05.01.06

Resumen. El artículo revisa las rivalidades entre los principales poetas del Siglo de Oro, sobre todo en torno al teatro. Se comentan las relaciones de amistad o enemistad entre Lope, Góngora, Tirso, Cervantes, Calderón... en el marco de la batalla por el aplauso popular y el medro social y económico.

Palabras clave. Rivalidad poética, teatro, Siglo de Oro.

Abstract. The article reviews the rivalries among the major poets of the Golden Age, particularly in the sphere of the theater. The papel examines the relations of friendship or enmity between Lope, Góngora, Tirso, Cervantes, Calderón... within the framework of the battle for popular applause and the social and economic thrive.

Keywords. Poetic Rivalry, Theater, Golden Age.

1. Esta artículo se enmarca en el proyecto FFI2014-52007-P, «Autoridad y poder en el teatro del Siglo de Oro. Estrategias, géneros, imágenes en la primera globalización», Ministerio de Economía y Competitividad, Gobierno de España (Dirección General de Investigación Científica y Técnica. Programa Estatal de Fomento de la Investigación Científica y Técnica de Excelencia). El trabajo procede de una conferencia pronunciada en la Fundación March, en Madrid. Conservo buena parte del tono oral y la perspectiva más bien divulgativa de mis comentarios, que quizá sea útil para los no especialistas en la materia; no tanto para los expertos. 
La competencia por el aplauso que enfrenta a los poetas del Siglo de Oro no consiste solo en unas cuantas escaramuzas. Se trata de una guerra con distinta intensidad, que responde a varias causas y que se libra en diferentes campos de batalla, uno de ellos, y muy especial, el del teatro.

Para entender mejor la disputa por el aplauso en las tablas hay que situarla en el panorama más amplio de las rivalidades literarias. Los poetas luchan por dos objetivos fundamentales: el medro y la gloria, los beneficios materiales y la fama artística.

Para lo primero dependen en buena parte de la protección de los nobles mediante el mecenazgo ${ }^{2}$. Una modalidad habitual era la de aceptar a un escritor como secretario o servidor, con puesto fijo en nómina (meta que no resulta siempre fácil de conseguir a los escritores). La relación de ingenios auriseculares que ejercieron de secretarios o criados de cierta relevancia en casas de nobles sería larga.

El caso del duque de Sesa, y de Lope, siempre necesitado de fondos, es uno de los más significativos.

Pérez de Montalbán en la Fama póstuma³ , habla de las economías de Lope con tonos admirativos:

Fue el poeta más rico y más pobre de nuestros tiempos. Más rico porque las dádivas de los señores y particulares llegan a diez mil ducados; lo que le valieron las comedias, contadas a quinientos reales, ochenta mil ducados; los autos seis mil; la ganancia de las impresiones mil y seiscientos, y los dotes de entrambos matrimonios siete mil, que hacen más de cien mil ducados [...] sin otras liberalidades secretas de tanta cantidad, que hablando una vez el mismo Lope de las finezas del duque de Sessa, su señor, aseguró que le había dado en el discurso de su vida veinticuatro mil ducados en dinero...

La cuenta de Montalbán suma casi 130.000 ducados. En el Quijote Sancho Panza dice haber ganado dos ducados mensuales al servicio del padre de Sansón Carrasco. Para ganar lo mismo que Lope Sancho debería trabajar más de cinco mil años... La dote que llevó Catalina de Salazar a su matrimonio con Cervantes, fue de 596 ducados con los que se podían comprar unos cuarenta bueyes. Un buey costaba 15 ducados, una ternera $5 . .$.

Esta protección podía verse amenazada por las solicitudes de otros rivales. Cuando a fines de 1613 Andrés de Almasa y Mendoza, una especie de agente de Góngora en la corte ${ }^{4}$, empieza a repartir las Soledades, las acompaña de unas Advertencias para la recta inteligencia de las Soledades, que dedica al duque de Sessa, patrón de Lope. La preocupación artística que debió de provocar a Lope la

2. Ver Arellano 1998.

3. Pérez de Montalbán, Fama póstuma a la vida y muerte del doctor frey Lope Félix de Vega Carpio, p. 30.

4. Ver Osuna Cabezas, 2006. 
importancia evidente del poema gongorino, y el intento de captar a un mecenas ya asignado, provocó una fuerte reacción ${ }^{5}$. Corrían rumores de que eran «grandes señores» los que habían incitado a Góngora a trasladarse a la corte: todo anunciaba para Lope la consolidación de su rival en el mundo aristocrático que a él le resultaba de difícil acceso, entre otras razones por su condición plebeya y su vida a menudo escandalosa.

Y así estallan las polémicas en torno a la nueva poesía, atizadas por Lope y sus seguidores. Para el prestigio de un poeta el teatro, género popular, no significaba mucho. Góngora, que apenas escribió tres comedias sin relevancia en la historia del teatro, pudo sentir la tentación de oponer sus piezas clasicistas a la nueva comedia lopiana, pero se trata de un episodio muy secundario. El enfrentamiento se produjo entre la poesía culta y la poesía llana.

Cada vez que sale una obra de Lope la recibe Góngora con un desprecio. En el soneto «A un señor que le envió La Dragontea de Lope de Vega» dice que «para ruido de tan grande trueno / es relámpago chico», y que «potro es gallardo, pero va sin freno»; para La Arcadia, donde Lope había puesto un inventado escudo nobiliario, responde con el famoso «Por tu vida, Lopillo, que me borres / las diez y nueve torres del escudo / porque aunque todas son de viento, dudo/ que tengas viento para tantas torres»; etc. Y se burla de la «llaneza» de la poesía castellana de Lope y seguidores en el tantas veces citado

$$
\begin{aligned}
& \text { Patos de la aguachirle castellana, } \\
& \text { que de su rudo origen fácil riega, } \\
& \text { y tal vez dulce inunda nuestra Vega, } \\
& \text { con razón Vega por lo siempre llana: } \\
& \text { pisad graznando la corriente cana } \\
& \text { del antiguo idioma y, turba lega, } \\
& \text { las ondas acusad cuantas os niega } \\
& \text { ático estilo, erudición romana. }
\end{aligned}
$$

Sobre el teatro de Lope es conocido el juicio de don Luis, para quien «los versos de Lope de Vega, en sacándolos del teatro son como los buñuelos, que en enfriándose no vuelven a tomar la sazón que antes, aunque los vuelvan a la sartén» 6 .

Por su lado Lope de Vega aspiraba a la admiración de los doctos: quería ser -más que el ídolo popular que era entre las masas urbanas aficionadas al teatro- respetado por los más cualificados; quería ser, en una palabra, además de Lope, don Luis de Góngora, al cual, por cierto, elogia a menudo. En la «Carta que se escribió echadiza a don Luis de Góngora»?, inspirada seguramente por Lope, se contrapone la actitud de Góngora, siempre agresiva, frente a la de Lope mismo:

él no le escribió en ofensa suya, y que se engañó Mendoza, pues mal pudiera hacer esto quien en las desgracias que aquí sucedieron a sus Soledades escribió

5. Ver Roses Lozano, 1994

6. Cito por Orozco, 1973, p. 400.

7. Ver el texto en Orozco, 1973, pp. 263-266 
aquel tan elegante como mal agradecido soneto que comienza: Canta, cisne andaluz. De suerte que todo su estudio de vuesa merced es solicitar el deshonor de este hombre, y todo el suyo celebrar su ingenio de vuesa merced...

El soneto a que se refiere la pluma anónima es el conocido:

\author{
Canta, cisne andaluz, que el verde coro \\ del Tajo escucha tu divino acento, \\ si, ingrato, el Betis no responde atento \\ al aplauso que debe a tu decoro... \\ Más de tu Soledad el eco adoro \\ que el alma y voz de lírico portento, \\ pues tú solo pusiste al instrumento, \\ sobre trastes de plata, cuerdas de oro. \\ Huya con pies de nieve Galatea, \\ gigante del Parnaso, que en tu llama, \\ sacra ninfa inmortal, arder desea, \\ que como, si la envidia te desama, \\ en ondas de cristal la lira orfea, \\ en círculos de sol irá tu fama.
}

Con ese soneto cerraba Lope su reflexión sobre la nueva poesía que inserta en La Filomena, donde leemos entre otras cosas:

El ingenio deste caballero [Góngora], [...] es el más raro y peregrino que he conocido en aquella provincia, y tal que ni a Séneca ni a Lucano, nacidos en su patria, le hallo diferente, ni a ella por él menos gloriosa que por ellos. [...] Escribió en todos estilos con elegancia [...] Mas [...] quiso [...] enriquecer el arte y aun la lengua con tales exornaciones y figuras, cuales nunca fueron imaginadas ni hasta su tiempo vistas [...] Y así, los que imitan a este caballero producen partos monstruosos que salen de generación, pues piensan que han de llegar a su ingenio por imitar su estilo. [...] para que mejor vuestra excelencia entienda que hablo de la mala imitación, y que a su primero dueño reverencio, doy fin a este discurso con este soneto que hice en alabanza deste caballero, cuando a sus dos insignes poemas no respondió igual la fama de su misma patria. (pp. 876-877, 887)

Las burlas al estilo culto procuran dejar al margen a Góngora, pero es evidente que en ocasiones a Lope le hubiera gustado decir algunas cosas más fuertes sobre su admirado rival, cuyas Solitúdines aparecen en otro famoso soneto paródico, este en La Dorotea:

Pululando de culto, Claudio amigo,

minotaurista soy desde mañana;

derelinquo la frasi castellana,

vayan las Solitúdines conmigo.

Por precursora, desde hoy más me obligo

al aurora llamar Bautista o Juana,

chamelote la mar, la ronca rana

mosca del agua, y sarna de oro al trigo. 


\begin{abstract}
Mal afecto de mí, con tedio y murrio, cáligas diré ya, que no griguiescos como en el tiempo del pastor Bandurrio. Estos versos, ¿son turcos o tudescos? Tú, letor Garibay, si eres bamburrio, apláudelos, que son cultidiablescos.
\end{abstract}

Es cierto que Lope había alcanzado una fama popular enorme. La gente rezaba un padrenuestro profano que prohibió varias veces la Inquisición, y que empezaba «Creo en Lope de Vega, poeta del cielo y de la tierra», pero no le bastaba. Además de aumentar la fama propia los poetas desean reducir la de sus rivales.

En este sentido los otros grandes escritores de la época como Quevedo o Cervantes no suponían mayores amenazas: Quevedo era poeta culto, pero no significaba la revolución de los grandes poemas de Góngora, y tampoco cultivaba el teatro. Don Francisco, exigente y mordaz, debió de respetar a Lope, aunque se despachó sin medida contra Montalbán, tan estrechamente ligado al fénix. De su amistad dan muestra los elogios mutuos que se dirigen. En una carta de enero de 1622 Lope trata a Quevedo de «gran don Francisco de Quevedo» («Oí un romance del gran don Francisco de Quevedo un día en que trataban desta materia con ingenioso estilo, diciendo que los calvos se reían de los teñidos, y los lampiños de los barbados, con otras cosas que fundaban bien las diferencias de las opiniones») ${ }^{8}$. En el Laurel de Apolo la alabanza a Quevedo parece menos formularia que en otros casos:

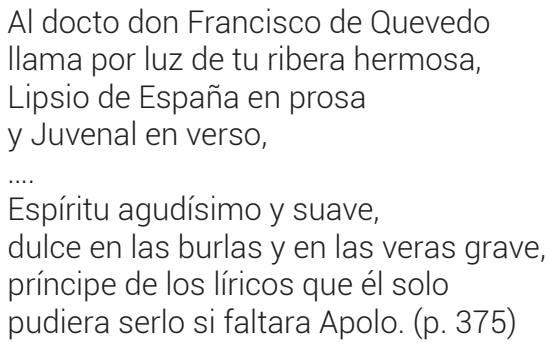

Quevedo, por su parte, corresponde con otra serie de ditirambos, entre los que valen como ejemplos el soneto laudatorio a El peregino en su patria, y la aprobación a las Rimas humanas y divinas del licenciado Tomé de Burguillos, donde escribe:

este libro cuyo título es Rimas del Licenciado Tomé de Burguillos, escrito con donaires, sumamente entretenido sin culpar la gracia en malicia, ni mancharla con el asco de palabras viles, hazaña de que hasta agora no he visto que puedan blasonar otras tales sino éstas. El estilo es, no sólo decente, sino raro, en que la lengua castellana presume vitorias de la latina, bien parecido al que solamente ha florecido sin espinas en los escritos de Frey Lope Félix de Vega Carpio, cuyo

8. Usaré la edición de González de Amezúa y doy sin más referencias de las fechas. El romance de Quevedo es «Chitona ha sido mi lengua» que lleva el estribillo «Todos somos locos, / los unos y los otros». Para textos con suficiente localización (pasajes del Quijote, aprobación de la Cuarta parte de Tirso, etc.) ahorro referencias bibliográficas. 
nombre ha sido universalmente proverbio de todo lo bueno, prerrogativa que no ha concedido la fama otro nombre...

En cuanto a Cervantes, carecía de todo prestigio social en la corte, y su afición al teatro era un completo fracaso. Debido probablemente a esa misma frustración el autor del Quijote empezaría una campaña contra la comedia nueva, que acabaría con su rendición.

El teatro comercial no implicaba tanto prestigio como otros géneros literarios, pero producía mayores beneficios. En las tablas se disputaban menos la fama entre lectores refinados, pero cuantos más rivales menos cantidad tocaba en el reparto.

El teatro era ya una empresa comercial que reportaba a Lope unos 500 reales por comedia (las necesidades vitales básicas podían cubrirse con unos 30 maravedíes diarios, 500 reales son 17.000 maravedíes) ${ }^{9}$.

El dramaturgo había de contar con el público: Lope se excusa de hablar en necio para dar gusto al vulgo, ya que el vulgo paga las comedias, y en una carta a un amigo (agosto 1604) señala que si algunos murmuran de su teatro pensando que escribe sus versos por opinión, «desengáñeles vuesa merced, y dígales que por dinero». Este escribir por dinero (Lope no lo hacía solo por dinero, pero también por dinero, claro) indignaba a algunos exquisitos que -como hoy sucede- pensaban que el arte no se puede someter a los mercados: el cura del Quijote (cap. 48), argumenta que el mal del teatro era que «las comedias se han hecho mercadería vendible»: si Cervantes mismo compartía esta idea debió de ser en aquellos momentos en los que no podía vender sus comedias porque las compañías solo querían las de Lope, como se queja también un triste poeta de la apócrifa Segunda parte del Guzmán de Alfarache que intenta vender sus obras al empresario Alonso de Heredia, causando la risa de todos con sus malos versos:

-Yo creo - se defiende- que vuesas mercedes tienen hecho el estómago al verso de Lope de Vega y no les parece nada bueno. (p. 551)

A pesar de ese casi monopolio de Lope en su época de auge, mira con recelo a otros dramaturgos, aunque tuviese con ellos buenas relaciones y gozase de la admiración de todos, entre los que destacan Pérez de Montalbán o Vélez de Guevara.

Alaba en distintas ocasiones a Guillén de Castro y Mira de Amescua, de cuya comedia La rueda de la Fortuna se burla, sin embargo, en una carta a Sessa (agosto, 1604), donde consigna además algunas prácticas curiosas del público toledano, al que se le había prohibido silbar, y que al no poder hacer ruidos con la boca, los hacía con el trasero:

representa Morales; silba la gente; unos caballeros están presos porque eran la causa desto; pregonose en el patio que no pasase tal cosa, y así apretados los toledanos por no silbar, se peen, que para el alcalde mayor ha sido notable desacato, porque estaba este día sentado en el patio. Aplacó esto porque hizo La rueda de la

9. Ver el pionero y documentado trabajo de Díez Borque, 1978 
Fortuna, comedia en que un rey aporrea a su mujer, y acuden muchos a llorar este paso, como si fuera posible.

A Lope, que fue acusado por los clasicistas de disparatar, le parece absurda una escena de Mira en la que un rey aporrea a su mujer: seguramente lo que de verdad molesta a Lope es que acudan muchos a llorar ese paso, es decir, el éxito popular y el impacto que la comedia de Mira causa en el público.

No parece que Ruiz de Alarcón fuese rival de importancia, pero en todo caso no se profesaban amistad. En la dedicatoria de Los españoles en Flandes, Lope alude a Ruiz de Alarcón, jorobado de pecho y espalda, al calificar de gente perversa y mala a los que tienen alguna deformidad; esos poetas ranas «en la figura y en el estrépito», que son jibones envidiosos. Verdad es que Ruiz de Alarcón también dirigió sus pullas al Fénix en Los pechos privilegiados, aludiendo a sus amoríos con Marta de Nevares:

$$
\begin{aligned}
& \text { Culpa a un viejo avellanado } \\
& \text { tan verde que al mismo tiempo } \\
& \text { que está aforrado de martas } \\
& \text { anda haciendo madalenos. (vv. 2168-2171) }
\end{aligned}
$$

Quizá molestara a Lope también el permiso que dan a Alarcón para publicar sus comedias, permiso que a él se le negaba, según se queja en una carta a Hurtado de Mendoza en abril de 1628:

Las Comedias de Alarcón han salido impresas (solo para mí no hay licencia): del vulgo se queja y le llama bestia fiera. Dicen que el vulgo ha vuelto por sí en una sonetada: si la cobro, la verá vuestra merced..

Tirso de Molina es uno de los seguidores más importantes de la fórmula de Lope, y uno de sus grandes admiradores. En distintas ocasiones defiende con entusiasmo a la comedia nueva, y a su principal inventor. En un extenso pasaje de La fingida Arcadia, inspirada en La Arcadia de Lope, elogia muchas obras de Lope, a quien compara con ventaja a Cicerón, Boccaccio, Ovidio, Ariosto oTasso:

ÁNGELA Pluma de Lope de Vega

la fama se deja atrás.

LUCRECIA ¡Prodigioso hombre! ¡No sé

qué diera por conocelle!

A España fuera por velle,

si a ver a Salomón fue

la celebrada etiopisa.

Lo que su fama me avisa,

lo que en sus escritos leo,

lo que enriquece su tierra,

lo que su espíritu encierra,

y lo que velle deseo, 


\author{
mi comparación excusa; \\ y a él le da más alabanza \\ lo que por su ingenio alcanza \\ que a esotro su ciencia infusa. (vv. 17-34)
}

Por boca de sus personaje Tirso pondera la condición amable y agradecida de Lope:

\author{
LUCRECIA ¿Agradece? \\ ÁNGELA Aunque hay alguno \\ que apasionado lo niega \\ es tan fértil esta vega \\ que paga ciento por uno. (vv. 103-106)
}

Sin embargo, con Tirso no resulta Lope muy generoso. En su aprobación a la Cuarta parte de comedias tirsianas escribe lo menos que puede:

La Cuarta parte de las comedias del maestro Tirso de Molina... no tiene cosa en que ofenda ni a nuestra Fe ni a las buenas costumbres. Muestra en ellas su autor vivo y sutil ingenio en los pensamientos, y sus estudios en todo género de letras con honestos términos tan bien considerados de su buen juicio. Puede concederle la merced que pide, etc.

Y en una carta de julio de 1615 apunta directamente contra la comedia de Don Gil de las calzas verdes, al comentar el escándalo de un celoso:

Perdía el tal hombre el juicio de celos [...] con tantos desaires, voces y desatinos, que se llegaba más auditorio que ahora tienen con Don Gil de las calzas verdes, desatinada comedia del mercedario.

Nótese de nuevo la referencia al abundante auditorio que tiene la comedia de Tirso, dato suficiente para que a Lope le parezca desatinada.

Se ofende de que lo mezclen con otros dramaturgos, aunque sean amigos, en una especie de desafío poético indigno de su categoría, como escribe a Hurtado de Mendoza en verano u otoño de 1628:

Estos días se decretó en el senado cómico que Luis Vélez, don Pedro Calderón y el dotor Mescua hiciesen una comedia, y otra en competencia suya el dotor Montalbán, el dotor Godínez y el licenciado Lope de Vega, y que se pusiese un jarro de plata en premio. Respondí que era este año capellán mayor de la Congregación, y que para el que viene acetaba el desafío. Grande invención, solene disparate, desautorizada cosa, gran plato para el vulgo...

Pero la enemistad y competencia más notable es la que lo relaciona con Cervantes, quien debió de ver con frustración que su propuesta teatral era ignorada, mientras triunfaba la de Lope, que en el fondo siempre le pareció superficial y hasta 
disparatada. Algunos textos evidencian sin muchos comentarios este vaivén de admiración y desprecio que se establece entre los dos. En el prólogo a las Ocho comedias y ocho entremeses incluye Cervantes este elogio para Lope, que no suena muy sincero:

Compuse en este tiempo hasta veinte comedias o treinta, que todas ellas se recitaron sin que se les ofreciese prueba de pepinos ni de otra cosa arrojadiza; [...] tuve otras cosas en que ocuparme; dejé la pluma y las comedias y entró luego el monstruo de naturaleza, el gran Lope de Vega, y alzose con la monarquía cómica: avasalló y puso debajo de su jurisdicción a todos los farsantes. Llenó el mundo de comedias propias, felices y bien razonadas, y tantas, que pasan de diez mil pliegos los que tiene escritos..

Y en el Viaje del Parnaso lo llama poeta insigne:

a cuyo verso o prosa

ninguno le aventaja ni aun le llega. (vv. 389-390)

Lope corresponde en el Laurel de Apolo, silva VIII:

la fortuna envidiosa

hirió la mano de Miguel Cervantes, pero su ingenio en versos de diamantes los de plomo volvió con tanta gloria que por dulces, sonoros y elegantes dieron eternidad a su memoria...

Es raro este elogio precisamente a los versos cervantinos, que no son gran cosa. En una carta de agosto de 1604 a un amigo de Valladolid Lope no es tan complaciente:

De poetas no digo: buen siglo es éste. Muchos están en cierne para el año que viene, pero ninguno hay tan malo como Cervantes, ni tan necio que alabe a Don Quijote.

Si Lope había leído con prisa el Quijote recién impreso (en los últimos días de 1604, con pie de imprenta de 1605) poco hubieron de gustarle, los comentarios del canónigo sobre las comedias de su tiempo (cap. 48), que eran sobre todo las de Lope:

estas que ahora se usan, [...] todas o las más son conocidos disparates y cosas que no llevan pies ni cabeza, y, con todo eso, el vulgo las oye con gusto, y las tiene y las aprueba por buenas, estando tan lejos de serlo, y los autores que las componen y los actores que las representan dicen que así han de ser, porque así las quiere el vulgo, [...] y que a ellos les está mejor ganar de comer con los muchos que no opinión con los pocos [...] Y aunque algunas veces he procurado persuadir a los actores que se engañan en tener la opinión que tienen y que más gente atraerán y más fama cobrarán representando comedias que sigan el arte que no con las 
disparatadas, ya están tan asidos y encorporados en su parecer, que no hay razón ni evidencia que dél los saque.

A lo que el cura asiente:

habiendo de ser la comedia, según le parece a Tulio, espejo de la vida humana, ejemplo de las costumbres y imagen de la verdad, las que ahora se representan son espejos de disparates, ejemplos de necedades e imágenes de lascivia...

Que entre Cervantes y Lope había una tensa amistad muy precaria se trasluce en otros testimonios, como el del prólogo del Quijote apócrifo, en el que Avellaneda acusa a Cervantes de atacar a Lope envidiosamente:

él tomó por [medios] el ofender a mí, y particularmente a quien tan justamente celebran las naciones más extranjeras, y la nuestra debe tanto por haber entretenido honestísima y fecundamente tantos años los teatros de España con estupendas e innumerables comedias...

A lo que responde Cervantes en el prólogo de la segunda parte del Quijote, con palabras que suenan a ironía, pues ciertas ocupaciones de Lope si bien eran continuas no podían calificarse de «virtuosas»:

He sentido también que me llame envidioso [...] no tengo yo de perseguir a ningún sacerdote, y más si tiene por añadidura ser Familiar del Santo Oficio; y si él lo dijo por quien parece que lo dijo [Lope], engañose del todo en todo, que del tal adoro el ingenio, admiro las obras y la ocupación continua y virtuosa.

Cervantes tuvo que aceptar la fórmula de Lope, aunque a regañadientes, como reconoce en el diálogo de la Comedia y la Curiosidad de El rufián dichoso:

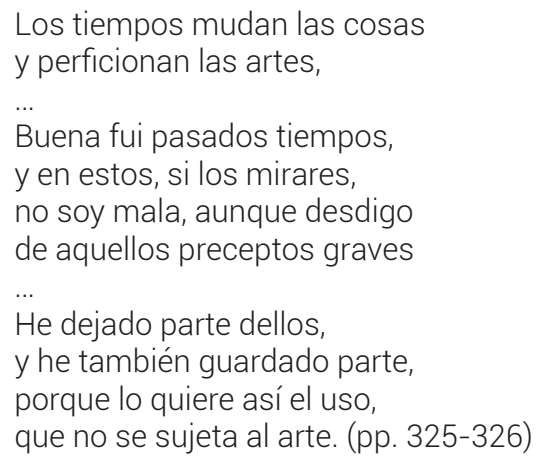

Pero ya era tarde para él: en 1615 Cervantes sabe que sus piezas teatrales no pueden competir; las relee y las encuentra «no tan malas que no mereciesen salir de las tinieblas»; por eso las publica, pero no consigue que suban a las tablas. Los empresarios o autores de comedias no las querían: 
En esta sazón me dijo un librero que él me las compraría [las comedias], si un autor de título no le hubiera dicho que de mi prosa se podía esperar mucho, pero que del verso, nada; $y$, si va a decir la verdad, cierto que me dio pesadumbre el oírlo (Ocho comedias, «Prólogo»).

Pesadumbre que confirman los mismos autores con su indiferencia:

Algunos años ha que volví yo a mi antigua ociosidad, y pensando que aún duraban los siglos donde corrían mis alabanzas, volví a componer algunas comedias; pero no hallé pájaros en los nidos de antaño; quiero decir que no hallé autor que me las pidiese, puesto que sabían que las tenía...

Cervantes no pudo, en suma, hacer a Lope ni a los demás dramaturgos de su tiempo, una competencia real.

Esta competencia se establecerá con la segunda generación que viene pisando fuerte en los escenarios comerciales y en el palacio.

Hacia 1629 Lope estaba otra vez intentando conseguir el puesto de cronista real, que le hubiera dado estabilidad económica, y planteándose el abandono del teatro: comenta al duque de Sesa en 1630:

Días ha que he deseado dejar de escribir para el teatro, así por la edad, que pide cosas más severas, como por el cansancio y aflicción de espíritu en que me ponen.

Sus comedias al parecer tenían algunos problemas con el público que hasta entonces le había seguido incondicionalmente:

con desagradar al pueblo dos historias que le di bien escritas y mal escuchadas [no sabemos qué comedias fueron estas] he conocido, o que quieren verdes años, o que no quiere el Cielo que halle la muerte a un sacerdote escribiendo lacayos de comedia...

Lope no logra sus esperanzas. El puesto de cronista lo conseguirá un joven erudito, José Pellicer, con quien Lope entabla una ácida disputa. Pellicer en sus Lecciones solemnes a las Soledades de Góngora, califica a este de mayor poeta de España, y critica a los envidiosos y enemigos ignorantes, en alusiones transparentes a Lope.

Viejo y melancólico, desengañado de los mecenas, sintiéndose abandonado por el público, Lope vuelve al teatro con algunas obras maestras como El castigo sin venganza, o Las bizarrías de Belisa.

Eran sus últimos intentos: en el final de las Bizarrías se dirige al público:

Senado ilustre, el poeta

que ya las musas dejaba

con deseo de serviros 
volvio esta vez a llamarlas

para que no le olvidéis... (vv. 2760-2764)

En esta pieza vuelve a criticar a los rivales, esos cultos que aun después de la muerte de Góngora, seguían cultivando con éxito un lenguaje como el de la Lucinda de la comedia,

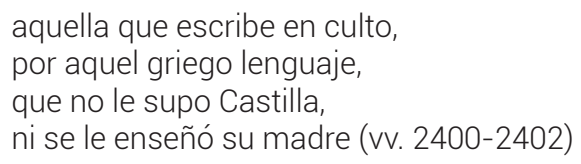

Los pájaros nuevos (Pellicer, Calderón, Rojas, Coello) que identifica con los secuaces de la poesía culta, pertenecían a familias de cierto rango y tenían buena entrada en la corte. En la Égloga Amarilis de La vega del Parnaso, alude a ellos:

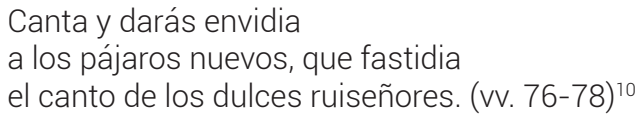

La Égloga a Claudio (1632) es un verdadero manifiesto contra los jóvenes dramaturgos y una reclamación de respeto por haber sido el creador de la comedia que ahora todos imitan usurpándole el aplauso y murmurando además:

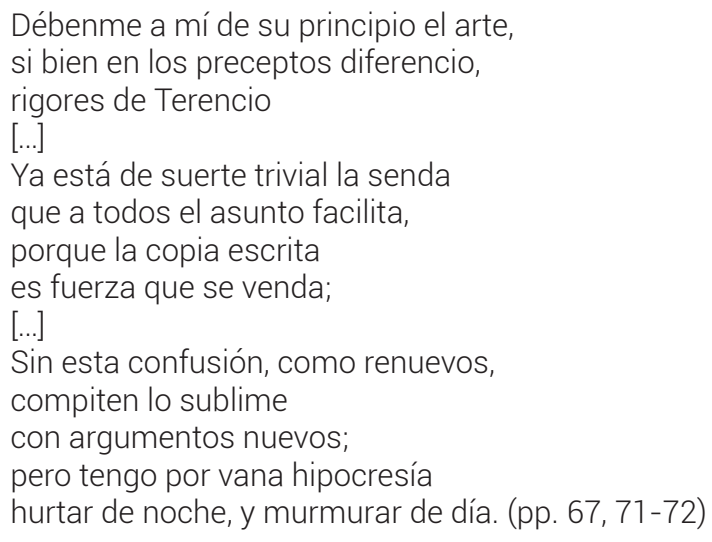

Lope debió de sentir celos de quienes le iban desplazando, especialmente Calderón, quien lo cita con elogio en varias comedias, pero que era sin duda un rival peligroso.

Algunos detalles sugieren el desagrado de Lope. En enero de 1629, el actor Pedro de Villegas hiere a un hermano de Calderón, y este allana el convento de las Trinitarias, donde se había refugiado el cómico, y donde estaba de monja una hija de Lope, el cual se queja del abuso: 
Grande ha sido el rigor buscando a Pedro de Villegas: el monasterio roto, la clausura y aun las imágines...Yo estoy lastimado, tanto por todas como por mi hija. El delito es grande, pero ¿qué culpa tienen los inocentes? Mas ¿cuándo no la tuvieron los corderos de la hambre de los lobos?

El elogio correspondiente a Calderón en el Laurel de Apolo no puede ser más lacónico («en estilo poético y dulzura / sube del monte a la suprema altura», silva VII).

Es significativo que hasta 1630 más o menos muchas comedias que no eran de Lope se publicaran con su nombre, para hacerlas más atractivas. Incluso La vida es sueño apareció en una edición a nombre de Lope, pero en los años siguientes se invirtió la práctica y comedias de Lope empezaron a atribuirse a Calderón, manipulaciones que indican quién era el mejor reclamo de venta.

Sin duda la muerte de Lope en 1635 aceleró el proceso. Las comedias nuevas ansiadas por el público no podían ya serle atribuidas, y se produce el relevo. Como el propio Lope había asumido desengañado:

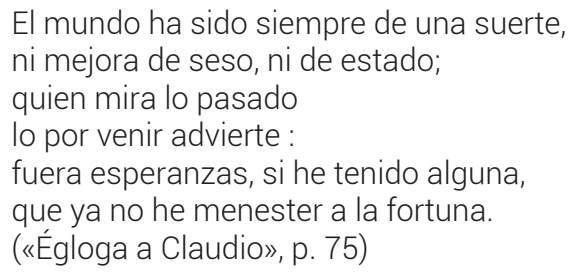

La batalla por el aplauso había terminado. Calderón dominará la escena sin grandes rivales. Su seguidor más notable y heredero como dramaturgo oficial de corte, Francisco Antonio Bances Candamo, será ya una figura poco relevante en la historia del teatro español. Incluso después de muerto Calderón, sus autos sacramentales siguen representándose, en detrimento de los de Bances y otros, que compiten sin esperanzas: en la loa para El primer duelo del Mundo, escribe Bances:

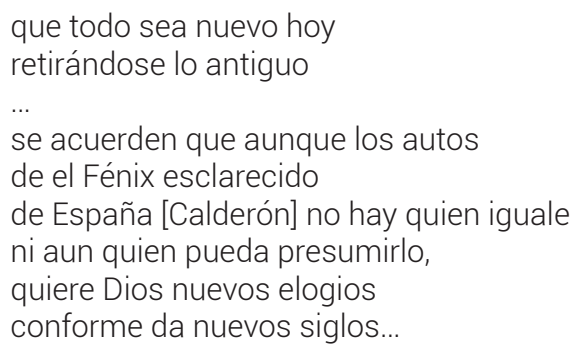

Pero a veces las cosas son injustas. Calderón resultaba imbatible: esta loa de Bances en la que defiende precisamente los autos nuevos frente al monopolio calderoniano, la imprimió en su gran colección de autos calderonianos Pedro Pando y Mier como loa nada menos que para El gran teatro del mundo. 
Lope, por único y extraordinario, había sido llamado el fénix de los ingenios; Calderón era también otro pájaro que volaba demasiado alto.

\section{BIBLIOGRAFÍA}

Arellano, Ignacio, «Algunos aspectos de la relación literatura-nobleza en el Barroco», Il Confronto letterario, 15, 30, 1998 [pero 2000], pp. 331-353. Disponible en línea: <http://hdl.handle.net/10171/19208> [07/12/2016].

Arellano, Ignacio y Miguel Zugasti, «La loa sacramental del Primer duelo del mundo. Materiales para el estudio del género en Bances Candamo», en Homenaje a Hans Flasche: Festschrift zum 80. Geburstag am 25. November 1991, ed. Karl-Hennarm Korner y Günther Zimmermann, Stuttgart, Steiner, 1991, pp. 205-224. Y en Bances Candamo, Francisco, Obras completas, I. Poesías cómicas, 1, ed. Ignacio Arellano, coord. Blanca Oteiza, Madrid/Frankfurt, 2014, pp. 47-62.

Cervantes, Miguel de, El rufián dichoso, en Teatro completo de Cervantes, ed. Antonio Rey Hazas y Florencio Sevilla, Barcelona Planeta, 1987.

Díez Borque, José María, Sociedad y teatro en la España de Lope de Vega, Barcelona, Antoni Bosch, 1978.

Luján de Saavedra, Mateo, Segunda parte del Guzmán de Alfarache, ed. David Mañero, Madrid, Cátedra, 2007.

Orozco, Emilio, Lope y Góngora frente a frente, Madrid, Gredos, 1973.

Osuna Cabezas, María José, «El papel de Almansa y Mendoza en la polémica gongorina», en Edad de oro cantabrigense: actas del VII Congreso de la Asociación Internacional de Hispanistas del Siglo de Oro, coord. Anthony J. Close y Sandra María Fernández Vales, Cambridge, Asociación Internacional del Siglo de Oro, 2006, pp. 489-494.

Pérez de Montalbán, Juan, Fama póstuma a la vida y muerte del doctor frey Lope Félix de Vega Carpio, ed. Enrico di Pastena, Pisa, ETS, 2001.

Roses Lozano, Joaquín, Una poética de la oscuridad. La recepción crítica de las Soledades en el siglo XVII, London, Tamesis, 1994.

Ruiz de Alarcón, Juan, Los pechos privilegiados, ed. Agustín Millares Carlo, Madrid, Espasa Calpe, 1972.

Tirso de Molina, Cuarta parte de comedias, ed. Ignacio Arellano, Madrid/Pamplona, Instituto de Estudios Tirsianos, 1999.

Tirso de Molina, La fingida Arcadia, ed. Victoriano Roncero, Madrid/Pamplona, Instituto de Estudios Tirsianos, 2015.

Vega, Lope de, Epistolario de Lope de Vega, ed. Agustín G. de Amezúa, Madrid, Real Academia Española, 1989. 
Vega, Lope de, La Filomena, en Obras poéticas, I, ed. José Manuel Blecua, Barcelona, Planeta, 1969.

Vega, Lope de, «Égloga a Claudio», en La vega del Parnaso, II, ed. Felipe B. Pedraza y Pedro Conde, Cuenca, Universidad de Castilla la Mancha, 2015.

Vega, Lope de, La vega del Parnaso, II, ed. Felipe B. Pedraza y Pedro Conde, Cuenca, Universidad de Castilla la Mancha, 2015.

Vega, Lope de, Las bizarrías de Belisa, ed. Alonso Zamora Vicente, Madrid, EspasaCalpe, 1963.

Vega, Lope de, Laurel de Apolo, ed. Antonio Carreño, Madrid, Cátedra, 2007. 
